\title{
Fear of COVID-19 and general self-efficacy among Turkish teachers: Mediating role of perceived social support
}

\author{
Emin Tamer Yenen ${ }^{1}$ (D) Ersoy Çarkit ${ }^{2}$ (D)
}

Accepted: 9 September 2021 / Published online: 20 October 2021

(c) The Author(s), under exclusive licence to Springer Science+Business Media, LLC, part of Springer Nature 2021

\begin{abstract}
Coronavirus-19 (COVID-19), which has influenced the world since the last months of 2019, has not only affected people physiologically, but also had serious adverse effects on mental health. Unavoidable increases in positive case numbers and loss of life have caused fear and anxiety, which is a psychological aspect of the COVID-19 outbreak. In this study, it was aimed to examine the mediating role of perceived social support in the relationship between teachers' general self-efficacy perceptions and their fear of COVID-19. The sample of the study consists of 322 Turkish teachers (198 women and 124 men; aged between 23 and 66 years). Data collection tools are the Fear of COVID-19 Scale, the General Self-Efficacy Scale, and the Perceived Multidimensional Social Support Scale. To test the model structural equation modeling and bootstrapping were used. In the study it was found that fear of COVID-19 has a negative impact on general self-efficacy and the perceived social support. Besides, it was found that perceived social support partially mediates the relationship between fear of COVID-19 and general self-efficacy. Thus, higher fear of COVID-19 was related to lower self-efficacy and perceived social support. In turn, higher perceived social support was associated with higher self-efficacy. The results were discussed within the framework of the literature, and implications presented.
\end{abstract}

Keywords Fear of COVID-19 · COVID-19 · Perceived social support · General self-efficacy · Teachers

\section{Introduction}

A coronavirus strain called COVID-19, which first appeared in the Wuhan region of China in December 2019 (Huang et al., 2020), continues to affect the whole world. COVID-19 is a deadly virus that causes severe acute respiratory infections (Zhou et al., 2020). This virus, which has become a global problem, was declared a pandemic by the World Health Organization (WHO) on 11 March 2020 due to its widespread and deadly effects (World Health Organization, 2020). As of April 2021, this disease unfortunately continues to spread, with approximately 135 million confirmed

Emin Tamer Yenen

emintameryenen@nevsehir.edu.tr

Ersoy Çarkit

carkitersoy@nevsehir.edu.tr

1 Faculty of Education, Department of Educational Seciences, Nevşehir Hacı Bektaş Veli University, Nevşehir, Turkey

2 Faculty of Education, Department of Educational Seciences, Psychological Counseling and Guidance, Nevşehir Hacı Bektaş Veli University, Nevşehir, Turkey cases and nearly three million deaths (World Health Organization, 2021) in 223 countries.

COVID-19 not only affects people physiologically, but also psychologically (Ahorsu et al., 2020; Çarkıt, 2021; Duan \& Zhu, 2020; Fitzpatrick et al., 2020; Gao et al., 2020; Gündoğan, 2021; Haktanir et al., 2020). The uncertainty in the course of the pandemic has affected millions of people around the world individually and socially for many years, as well as causing side effects such as depression, traumatic stress and anxiety (Zandifar \& Badrfam, 2020). People's anxiety and fear of catching COVID-19 is explained with the concept of fear of COVID-19 (Ahorsu et al., 2020). Studies in the related literature reveals that fear of COVID-19 causes cognitive and behavioral disorders in individuals (Fitzpatrick et al., 2020); decreases life satisfaction (Sat1c1 et al., 2020a, b); increases the level of fear and anxiety (Bitan et al., 2020; Cao et al., 2020; Wang et al., 2020), burnout (Yakut et al., 2020), and hopelessness (Sarıçalı et al., 2020); lowers motivation (Taşç1, 2021) and mental well-being (Satıc1 et al., 2020a, b). Smilarly, studies show that the fear of COVID-19 negatively affects the emotional self-efficacy of public employees (Çiçek \& Almalı, 2020) and reduces 
the perceived level of social support (Yakut et al., 2020). In this context, the mediating role of perceived social support in the relationship between fears of COVID-19 and general self-efficacy was examined in the sample of teachers who constitute the largest number of public employees in Turkey.

\section{Self efficacy}

Self-efficacy is the perception of an individual's capacity to organize and successfully perform the necessary activities to produce a certain performance (Bandura, 1977). Bandura (2006, p. 170) argues that there is nothing more central or more dominant than personal self-efficacy beliefs in people's making choices and implementing these choices and that this core belief is the basis of human behavior. Low selfefficacy results in helplessness, avoidance, or withdrawal (Zimmerman, 1989). Bandura (1977) stated that there are four main sources of self-efficacy (performance experiences, indirect experiences, verbal persuasion and emotional states). Approval by others, social support for doing a job, and emotional states of a person are important factors affecting self-efficacy (Bandura, 1995). However, fear and anxiety can negatively affect self-efficacy (Bandura, 1995). Bandura (1995) explains this situation as fallows: Positive emotional states increase people's self-efficacy perceptions, while anxiety and hopelessness decrease their self-efficacy perception.

Considering the negative impact of the COVID-19 today, it is thought that the self-efficacy of individuals is affected by this anxiety environment. Therefore, it was hypothesized that fear of COVID-19 will be negatively associated with general self-efficacy (Hyphothesis 1). On the other hand, as Bandura (1977) stated in his theory, external social supports positively affect the self-efficacy of the individual. Therefore, it was hypothesized that perceived social support will be positively associated with general self-efficacy (Hyphothesis 2).

\section{Perceived social support}

Social support can be defined as the support that increases psychological dynamics and contributes to the individual in terms of affective, physical and cognitive aspects and is received from family, friends, neighbors and institutions (Gülaçt, 2010). There are many studies showing that social support has a positive relationship with mental and physical health (Fenlason \& Beehr, 1994; Gülaçtı, 2010; Hupcey, 1998; Poudel et al., 2020). For example, Gülaçtı (2010) found that social support, especially from the family, positively affected subjective well-being. Similarly, Poudel et al. (2020) determined that perceived social support positively affects psychological well-being through self-esteem.
Therefore, it was hypothesized that fear of COVID-19 will be negatively associated with perceived social support (Hyphothesis 3).

With social support, the harmful psychological effects of stress can be lessened by reducing the level of stress exposure (Towner, 1998). In community mental health care studies, it is stated that social support systems provided by family, friends and close environment play an important role in facilitating or making the solutions of psychological problems easier (Eker et al., 2001). Therefore, perceived social support may act as a buffer against the negative impact of fear of COVID-19 on teachers' general self-efficacy. Namely, perceived social support will mediate the relationship between fear of COVID-19 and general self-efficacy (Hyphothesis 4).

\section{Present study}

Daily life has significantly changed due to measures such as quarantine practices, school closures, social isolation and housing orders (Shanafelt et al., 2020). In addition, some measures such as curfew restrictions, social distancing limits, regulations in working hours, which are applied all over the world in combating the outbreak, may negatively affect people's perceptions of social support (Tull et al., 2020). For example, Ar1 (2020) reported that the family atmosphere was negatively affected by the pandemic restrictions and it became difficult to meet psychological needs. It is thought that the restrictions and changes brought about by the pandemic process make social support more important. Furthermore, related researches reported that anxiety of COVID-19 decreased perceived social support (Grey et al., 2020; Yakut et al., 2020). In addition, fear of covid reduces people's confidence in their abilities to cope with problems (Cao et al., 2020). However, social support increases self-efficacy (Bandura, 1995). For this reason, it is thought that people need social support more than ever due to the COVID-19 threat that has affected the world.

In this study, it was aimed to examine the mediating role of perceived social support in the relationship between teachers' fear of COVID-19 and their general self-efficacy perceptions. In previous studies, the relationship of fear of COVID-19 to emotional self-efficacy (Çiçek \& Almalı, 2020) and social support (Gray, et al., 2020) was examined. However, the mediating effect of perceived social support in the relationship between fear of COVID-19 and selfefficacy was not studied. In addition, this research was carried out on a sample of teachers who form an important and large part of educational environments. Teachers are the main actors of the education system and development movements (Gomendio, 2017). Teachers are the people who organize the educational environment, guide students, show 
them the learning paths and facilitate learning. However, the pandemic process we are in has negatively affected teachers like everyone else. Particularly, there are reported studies that teachers have faced problems such as low student motivation in the distance education process, students' indifference to lessons, high level of anxiety, difficulty in eliminating students' despair, and inability to communicate in the COVID-19 pandemic process (Çakın \& Külekçi Akyavuz, 2020; Demir \& Özdaş, 2020). This situation indicates that the outbreak process may affect the self-efficacy of teachers and that they may need support while trying to provide social support to their students in order to motivate them.

Examining the relationships among teachers' fears of COVID-19, perceived social support, and the general selfefficacy will make suggestions for future research and practitioners. In the light of the above theoretical and empirical findings, the hypotheses and the hypothesis model (Fig. 1) are presented below:

Hyphothesis 1. Fear of COVID-19 will be negatively related to general self-efficacy.

Hyphothesis 2. Perceived social support will be positively related to general self-efficacy.

Hyphothesis 3. Fear of COVID-19 will be negatively related to general perceived social support.

Hyphothesis 4. Perceived social support will mediate the relationship between fear of COVID-19 and general self-efficacy.

\section{Method}

\section{Participants}

The participants of the study are 322 Turkish teachers (198 women-61.5\%; 124 men-38.5\%). The convenience sampling method was used in the study. The age of the participants range from 23 to $66\left(\mathrm{M}_{\text {age }}=35.21, \mathrm{SD}=7.92\right) .128$
(39.8\%) participants work in primary schools, 93 (28.9\%) participants work in middle schools, 68 (21.1\%) participants in high schools, 25 (7.8\%) participants in the pre-school institutions, 4 (1.2\%) participants in guidance and research centers, and 4 (1.2\%) participants in special education schools. Participant characteristics are included in Table 1.

\section{Measures}

Fear of COVID-19. Participants' fear of COVID-19 was measured using the Fear of COVID-19 Scale (Ahorsu et al., 2020). Turkish adaptation studies of the Fear of COVID-19 Scale were performed by Satıc1 et al. (2020a). The Fear of COVID-19 Scale consists of 7 items (e. g. "It makes me uncomfortable to think about coronavirus-19." and "I am afraid of losing my life because of coronavirus-19."). Participants' answers to the items range from strongly disagree (1) to strongly agree (5). Confirmatory factor analysis of the Turkish version of Fear of COVID-19 Scale yielded goodness of fit indices within acceptable limits (e. g., SRMR $=0.061 ; \mathrm{IFI}=0.915 ; \mathrm{CFI}=0.915)$. As expected, the Fear of COVID-19 Scale was found to be positively correlated with psychological distress and negatively correlated with life satisfaction. The Cronbach Alpha coefficient of the Fear of COVID-19 Scale was found to be 0.84 (Satic1 et al., 2020a, b). In this study, the Cronbach Alpha coefficient of the Fear of COVID-19 Scale was found to be 0.90 .

General self-efficacy. Participants' self-efficacy beliefs were measured with the Generalized Self-Efficacy Scale (Schwarzer \& Jerusalem, 1995). Turkish adaptation studies of the Generalized Self-Efficacy Scale were conducted by Aypay (2010). Generalized Self-Efficacy Scale consists of 10 items (e. g. "Thanks to my resourcefulness, I know how to handle unforeseen situations." and "I can remain calm when facing difficulties because I can rely on my coping abilities."). Participants' answers to the items range from not at all true (1) to exactly true (4). Turkish version of the Generalized Self-Efficacy Scale was found to be positively

Fig. 1 Hypoyhesis model

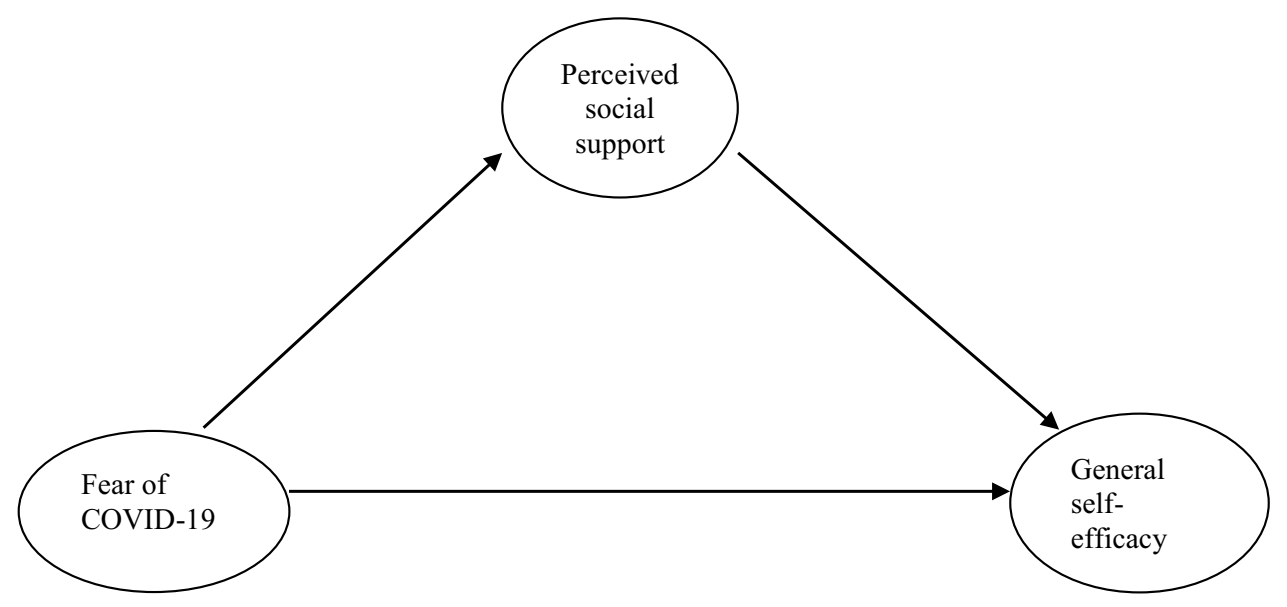


Table 1 Participant characteristics

\begin{tabular}{lll}
\hline Variables & Frequency & $\%$ \\
\hline Gender & & 61.5 \\
Woman & 198 & 38.5 \\
Man & 124 & \\
In which school level or institution do you work? & & 7.8 \\
Pre-school & 25 & 39.8 \\
Primary school & 128 & 28.9 \\
Middle school & 93 & 21.1 \\
High school & 68 & 1.2 \\
Guidance and research center & 4 & 1.2 \\
Special education school & 4 & 14 \\
Have you infected with COVID-19 disease? & & 86 \\
Yes & 45 & \\
No & 277 & 74.2 \\
Have any of your relatives infected with COVID-19 disease? & & 25.8 \\
Yes & 239 & \\
No & 83 & 26.7 \\
Have any of your relatives died due to COVID-19? & & 73.3 \\
Yes & 86 & 236 \\
No & &
\end{tabular}

correlated with dealing with problem-focused stress and self esteem. Test-retest stability coefficient of the Generalized Self-Efficacy Scale was found to be 0.80 . The Cronbach Alpha coefficient of the Generalized Self-Efficacy Scale was found to be 0.83 (Aypay, 2010). In this study, the Cronbach Alpha coefficient of the Generalized Self-Efficacy Scale was found to be 0.95 .

Perceived social support. Social support perceptions of the participants were measured with the Multidimensional Scale of Perceived Social Support (MSPSS; Zimet et al., 1988). The Turkish adaptation studies of the Multidimensional Scale of Perceived Social Support were conducted by Eker et al. (2001). MSPSS consists of 12 items (e. g. "There is a special person in my life who cares about my feelings.", "I can talk about my problems with my friends." and "I get the emotional help and support I need from my family.") and 3 subscales (family support, friends support, significant other support). Participants' answers to the items range from very strongly disagree (1) to very strongly agree (7). Turkish MSPSS was found negative correlation with hopelessness, loneliness, and negative social relationships. The Cronbach Alpha coefficient of the MSPSS was found to be 0.89 (Eker et al., 2001). In this study, the Cronbach Alpha coefficient of the MSPSS was found to be 0.92 .

\section{Procedure and analyses}

Before starting the research, an approval was obtained from the university ethics committee of the researchers. Data from the participants were collected online. Only volunteers answered the scale set. Before responding to the scale set, the participants approved the consent form, which includes information about the study purpose, content, and the process of the study. The collected data were evaluated collectively by the researchers. Descriptive statistics, correlation analysis, confirmatory factor analysis, and structural equation modeling were used in the analysis of the data. The COVID-19 Fear and General Self-Efficacy latent variables were represented by three parcels each to reduce complexity and increase reliability. For item parceling, after confirmatory factor analysis was performed for each scale, it was created by assigning the items to the parcels in order according to their factor loads (Little et al., 2002). Before the mediation analysis, the assumptions were checked. Subsequently, confirmatory factor analyses of the measurement tools were made with the collected data and the measurement model tested. Among the fit statistics suggested in the literature (Browne \& Cudeck, 1993; Byrne, 2010; Schermelleh-Engel et al., 2003), $\mathrm{x}^{2}$ / df (<5); Comparative Fit Index (CFI $>0.90)$, Root Means Square Error Approximation (RMSEA <0.10), Tucker-Lewis Index (TLI > 0.90) were used. Finally, mediation analysis was examined using the maximum likelihood method and 10,000 bootstrapping at 95 confidence intervals (C1s).

\section{Results}

\section{Preliminary analyses}

The collected data were evaluated in terms of missing values, outliers, and normal distribution. There is no 
Table 2 Correlations and descriptive statistics

\begin{tabular}{llllrlll}
\hline & 1 & 2 & $\mathrm{M}$ & \multicolumn{1}{c}{ SD } & Skewness & Kurtosis & $\mathrm{a}$ \\
\hline 1. Fear of COVID-19 & & & 18.27 & 7.17 & .390 & -.542 & .90 \\
2. Perceived Social Support & -.12 & & 66.53 & 16.17 & -.683 & -.495 & .92 \\
3. General Self-efficacy & -.18 & .43 & 33.65 & 6.25 & -.942 & .508 & .95 \\
\hline
\end{tabular}

$N=322$. All correlations are significant in the .05 level missing data as the data were collected online. Outliers were checked with the Mahalanobis distance test. No outliers were found in the data set. The skewness and kurtosis values of all variables were in the range of \pm 1.5 . Relationships between variables ranged from -0.18 to 0.43 . (Table 2). All assumptions were met in accordance with Tabachnick and Fidell's (2013) views.

Confirmatory factor analyses of the scales used in the study were done. The goodness of fit indices of the Fear of Covid-19 Scale $\left(\mathrm{x}^{2} / \mathrm{df}=2.99 ; \mathrm{CFI}=0.98\right.$; TLI $=0.97$; RMSEA $=0.079)$, the Perceived Multidimensional Social Support Scale $\left(\mathrm{x}^{2} / \mathrm{df}=2.97 ; \mathrm{CFI}=0.97 ; \mathrm{TLI}=0.96\right.$; RMSEA $=0.078)$, and the General Self-Efficacy Scale $\left(\mathrm{x}^{2} /\right.$ $\mathrm{df}=3.81 ; \mathrm{CFI}=0.97 ; \mathrm{TLI}=0.95 ; \mathrm{RMSEA}=0.094)$ were within acceptable levels. The factor load of all items in all three scales was found to be greater than 0.32 and statistically significant. The goodness of fit indices $\left(\mathrm{X}^{2} / \mathrm{df}=1.37\right.$; $\mathrm{CFI}=0.99$; $\mathrm{TLI}=0.99$; $\mathrm{RMSEA}=0.034$ ) for the measurement model was found to be at an acceptable level.

\section{Mediation analysis}

After the preliminary analyses and assumptions were checked, the structural model was tested (Fig. 2). The model yielded good fit indices $\left(\mathrm{X}^{2} / \mathrm{df}=1.37\right.$; $\mathrm{CFI}=0.99$; $\mathrm{TLI}=0.99$; $\mathrm{RMSEA}=0.034)$.
Analysis findings are presented in Table 3. The mediation model was tested for significance at $95 \%$ CI using the bootstrap estimation. Initially, fear of COVID-19 negatively predicted general self-efficacy $(\beta=-0.184, \mathrm{CI}=-0.295$, -0.068). When perceived social support was included in the model as a mediator variable, the path coefficient decreased ( $\beta=-0.114, \mathrm{CI}=-0.158,-0.005)$. However, the path coefficient was still statistically significant. Moreover, CI did not include zero. Therefore, perceived social support partially mediates the relationship between the fear of COVID-19 and the general self-efficacy. Fear of COVID-19 negatively predicted perceived social support $(\beta=-0.142, \mathrm{CI}=-0.285$, $-0.001)$. Perceived social support positively predicted general self-efficacy $(\beta=0.494, \mathrm{CI}=0.363,0.617)$.

\section{Discussion}

The current study aimed to examine the mediating role of perceived social support in the relationship between teachers' fear of COVID-19 and their general self-efficacy.

In the study, it was first hypothesized that there would be a negative relationship between fear of COVID-19 and general self-efficacy. In this study, a negative significant relationship was found between the fear of COVID-19 and general self-efficacy. According to this result, the hypothesis put
Fig. 2 Mediated structural model; GSE: General selfefficacy; PSS: Perceived social support; FCOVID19: Fear of COVID-19; FCP: Fear of COVID-19 parcel; SEP: Selfefficacy parcel

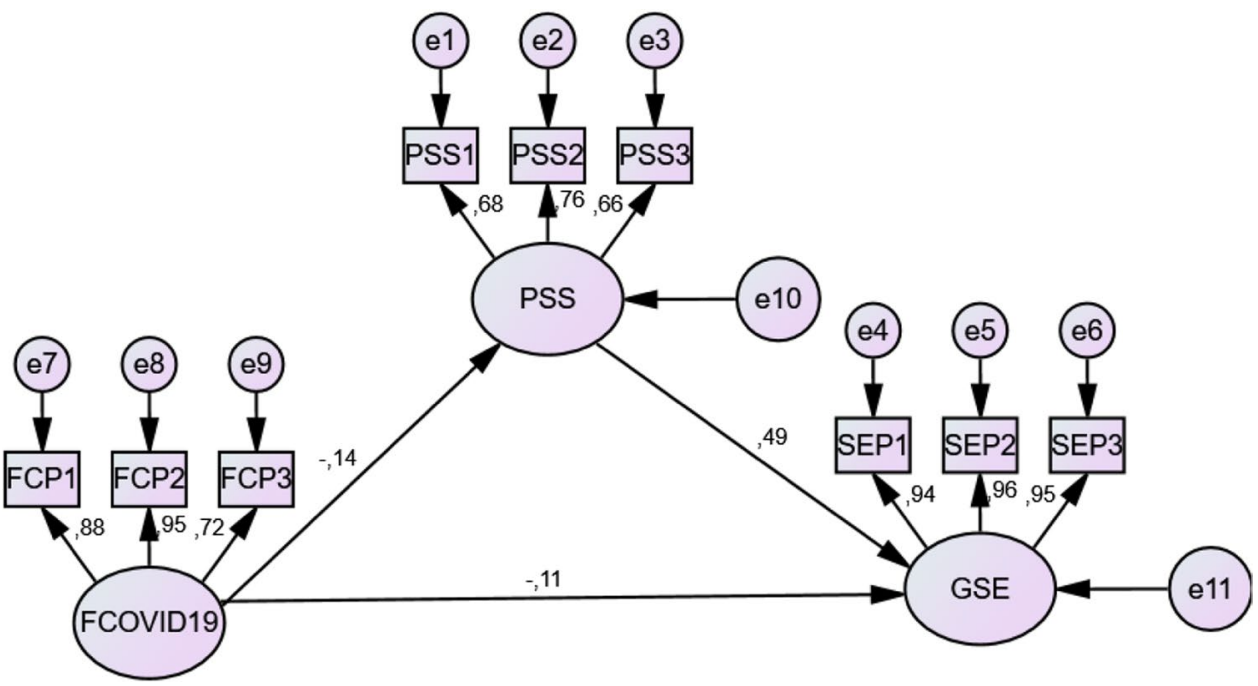


Table 3 Path coefficients

\begin{tabular}{lllll}
\hline & $\begin{array}{l}\text { Standardized } \\
\text { coefficients }\end{array}$ & $\mathrm{t}$ & Lower & Upper \\
\hline FCOV19 $\rightarrow$ GSE & -.184 & -3.164 & -.295 & -.068 \\
FCOV19 $\rightarrow$ PSS & -.142 & -2.116 & -.285 & -.001 \\
PSS $\rightarrow$ GSE & .494 & 7.075 & .363 & .617 \\
FCOV19 $\rightarrow$ PSS $\rightarrow$ GSE & -.114 & -2.115 & -.158 & -.005 \\
\hline
\end{tabular}

FCOV19: Fear of COVID-19; GSE: General self-efficacy; PSS: Perceived social support

forward is supported. This result can be interpreted that the fear of COVID-19 affects the general self-efficacy of people negatively; that is, as the fear of COVID-19 increases, the self-efficacy of individuals decreases. The results of the current study are consistent with the results of the previous studies, which found a negative association between fear of COVID-19 and general self-efficacy (Mumtaz et al., 2021; Okan, 2021). Moreover, the results of this study support Bandura's (1995) view that positive mood increases perceived self-efficacy while a negative mood weakens it. Considering that fear of COVID-19 is undoubtedly a negative mood, the adverse impact of fear of COVID-19 on general self-efficacy found in this study is consistent with Social Cognitive Theory.

The second hypothesis investigated in the study was whether there is a relationship between the perceived social support and general self-efficacy. In this context, a positive significant relationship was found between the perceived social support and general self-efficacy. Namely, the second hypothesis was supported. This result can be interpreted that as perceived social support increases, general self-efficacy increases as well. This result is also consistent with the results of other studies in the literature (Albal \& Kutlu, 2010; Çavuş, 2009; Demir, 2019; Korte and Simonsen, 2018; Major et al., 1990; Yusoff, 2012). Albal and Kutlu (2010) found that perceived social support increased self-efficacy in coping with depression which is a psychological phenomenon. Similarly, Saltzman and Holahan (2002) stated that the relationship between self-efficacy and social support in coping with psychological problems is strong. In the case of teachers, Demir (2019) found that social support from family, partner, spouse, and friends increased teachers' self-efficacy. Similarly, Korte and ve Simonsen (2018) found that perceptions of support from family, society, and students contribute to teachers' self-efficacy and that perceived social support from students and society are the best predictors of teacher self-efficacy. As stated in the Social Cognitive Theory of Bandura $(1977,1995)$, the fact that one of the sources of self-efficacy of individuals is "verbal persuasion" supports these results.

Thirdly, in this study, it was investigated whether there is a relationship between fear of COVID-19 and the perceived social support. In this direction, it was determined that there is a negative significant relationship between the fear of COVID19 and the perceived social support. This result shows that the fear of COVID-19 lowers perceptions of social support. In other words, fear of COVID-19 may weaken people's perceptions of social support. The results reported in recent previous studies are also consistent with the result of this study (Grey et al., 2020; Moore et al., 2021; Skalski et al., 2021b; Yakut et al., 2020). When similar studies are examined; it is seen that the grief process brought about by COVID-19 reduces perceived social support (Skalski et al., 2021a); there is a negative relationship between stress experiences related to fear of COVID-19 and the perceived social support (Ye et al., 2020); perceived social support negatively predicts covid anxiety (Labrague \& De los Santos, 2020). When the results of the study are evaluated together, it can be said that the fear of COVID-19 causes people to think that they cannot get enough support from important people in the face of difficulties and so, they feel more alone. This may make them more vulnerable to mental health problems.

In the study it was found that the perceived social support partially mediates the relationship between fear of COVID 19 and general self-efficacy. This result shows that the hypothesis put forward is supported. This result can be interpreted as that fear experienced during the pandemic process affects the general self-efficacy perception less negatively in individuals who have social support from family, friend, partner, and spouse. In other words, perceived social support may reduce the negative impact of COVID-19 fear on self-efficacy. There is no direct study in the relevant literature to support these results. However, in a similar study examining the mediating role of perceived social support, Arıcı Özcan and Arslan, (2020) found that perceived social support acts as a mediator role between post-traumatic stress and post-traumatic growth, and that social support reduces stress levels. The results of the current study support the results of previous studies that revealed the importance of social support in protecting mental health during the pandemic process (Fang et al., 2021; Li et al., 2021). Therefore, it can be said that perceived social support may decrease the negative outcomes of fear of COVID-19 on self-efficacy.

\section{Limitations and future directions}

Despite its important findings, there are some limitations to consider in this study. Firstly, the data were collected from teachers in Turkey. It is necessary to generalize existing findings with other samples and in wider contexts. Studies involving participants from different countries and cultures and different professions can be organized in future research. Another limitation of this study is that the data were collected with scales with quantitative data collection tools. Data can be diversified with data collection 
methods such as observation and interview in order to gain more in-depth information. Moreover, in this study, data were collected cross-sectionally. Therefore, it is not possible to make causal inferences. Subsequent research can be conducted with longitudinal and experimental designs to make causal inferences.

Research results have shown that social support from family, friend, partner and spouse are important in reducing the negative outcomes of fear of COVID-19 on teachers' self-efficacy. In this context, social support perceptions can be increased by applying psychoeducational programs developed by Brand et al. (1995), and Mert and Iskender (2015) and which are reported to be effective for teachers. By developing an online version of these psychoeducational programs, their application during the pandemic process can be facilitated.

Considering the theoretical views (Bandura, 1977, 1995) that emotional states such as anxiety and fear, which are among the factors affecting self-efficacy, reduce the self-efficacy of individuals, it is thought that intervention programs to reduce the fear of COVID-19 are important. Given that the fear of COVID-19 is a negative emotion, teachers can be helped to cope with the fear of COVID-19 by developing group or individual intervention programs to increase emotion regulation and cognitive emotion regulation skills.

\section{Conclusion}

In conclusion, perceived social support reduces the negative impact of fear of covid on general self-efficacy and acts as a buffer. However, it was found that fear of COVID-19 had a negative impact on general self-efficacy and the perceived social support. In the study it was also found that there is a significant relationship between perceived social support and the general self-efficacy. According to these findings, it is thought that the self-efficacy of teachers whose general selfefficacy levels have decreased due to the fear of COVID-19 may be increased through social support.

Funding This research has not received specific support from public sector agencies, the commercial sector or non-profit organisations.

Data availability The datasets generated during and/or analyzed during the present study are available from the authors on reasonable request.

\section{Declarations}

Ethical approval All procedures performed in studies involving human participants were in accordance with the ethical standards of the institutional and/or national research committee and with the 1964 Helsinki declaration and its later amendments or comparable ethical standards.
Informed consent Informed consent was obtained from all individual participants included in the study.

Conflict of interest The authors declared no conflicts of interest with respect to the research, authorship, and/or publication of this article.

\section{References}

Ahorsu, D. K., Lin, C. Y., Imani, V., Saffari, M., Griffiths, M. D., \& Pakpour, A. H. (2020). The Fear of COVID-19 Scale: Development and initial validation. International Journal of Mental Health and Addiction. https://doi.org/10.1007/s11469-020-00270-8

Albal, E., \& Kutlu, Y. (2010). The relationship between the depression coping self-efficacy level and perceived social support resources. Journal of Psychiatric Nursing, 1(3), 115-120.

Arı, F. A. (2020). Adolescents' psychological needs and perceived family atmosphere during the Covid-19 epidemic process. Turkish Psychological Counseling and Guidance Journal, 10(59), $565-579$.

Arıcı Özcan, N., \& Arslan, R. (2020). The mediating role of perceived social support and spirituality in the relationship between posttraumatic stress level and posttraumatic growth. Electronic Journal of Social Sciences, 19(73), 299-314. https://doi.org/10.17755/ esosder.548142

Aypay, A. (2010). The Adaptation study of General Self-Efficacy (GSE) Scale to Turkish. Inonu University Journal of the Faculty of Education, 11(2), 113-131.

Bandura, A. (1977). Self-efficacy: Toward a unifying theory of behavioral change. Psychological Review, 84(2), 191-215. https://doi. org/10.1037/0033-295X.84.2.191

Bandura, A. (1995). Exercise of personal and collective efficacy in changing societies. In A. Bandura (Ed.), Self-efficacy in changing societies. Cambridge University Press.

Bandura, A. (2006). Toward a psychology of human agency. Perspectives on Psychological Science, 1(2), 164-1.

Bitan, D. T., Grossman-Giron, A., Bloch, Y., Mayer, Y., Shiffman, N., \& Mendlovic, S. (2020). Fear of COVID-19 scale: Psychometric characteristics, reliability and validity in the Israeli population. Psychiatry Research, 289, 1-5.

Brand, E. F., Lakey, B., \& Berman, S. (1995). A preventive, psychoeducational approach to increase perceived social support. American Journal of Community Psychology, 23(1), 117-135.

Browne, M. W., \& Cudeck, R. (1993). Alternative ways of assessing model fit. In K. A. Bollen \& J. S. Long (Eds.), Testing structural equation models (pp. 136-162). Sage.

Byrne, B. M. (2010). Structural equational modeling with AMOS: Basic concepts, applications and programming (2nd ed.). Routledge Taylor \& Francis Group.

Cao, W., Fang, Z., Hou, G., Han, M., Xu, X., Dong, J., \& Zheng, J. (2020). The psychological impact of the COVID-19 epidemic on college students in China. Psychiatry Research, 287, 112934. https://doi.org/10.1016/j.psychres.2020.112934

Çakın, M., \& Külekçi Akyavuz, E. (2020). The Covid-19 process and its reflection on education: An analysis on teachers' opinions. International Journal of Social Sciences and Education Research, $6(2), 165-186$.

Çarkit, E. (2021). Intolerance of uncertainty as a predictor of fear of COVID-19 in university students. Maarif Mektepleri International Journal of Educational Sciences, 5(1), 33-42. https://doi. org/10.46762/mamulebd.934997

Cavus, M. F. (2009). The effects of perceived social support on the self-efficacy among adolescents. Cag University Journal of Social Sciences, 6(2), 1-11. 
Çiçek, B., \& Almalı, V. (2020). The relationship between anxiety selfefficacy and psychological well-being during covid-19 pandemic process: Comparison of private and public sector employees. Electronic Turkish Studies, 15(4), 241-260. https://doi.org/10. 7827/TurkishStudies.43492

Demir, F., \& Özdaş, F. (2020). examining teachers' opinions related to distance education in the COVID-19 process. Journal of National Education, 49(1), 273-292.

Demir, S. (2019). Self-efficacy as an outcome of perceived social support. Inonu University Journal of the Faculty of Education, 20(3), 919-932.

Duan, L., \& Zhu, G. (2020). Psychological interventions for people affected by the COVID-19 epidemic. The Lancet Psychiatry, 7(4), 300-302. https://doi.org/10.1016/S2215-0366(20)30073-0

Eker, D., Arkar, H., \& Yaldız, H. (2001). Factorial structure, validity, and reliability of revised form of the Multidimensional Scale of Perceived Social Support. Turkish Journal of Psychiatry, 12(1), $17-25$.

Fang, X. H., Wu, L., Lu, L. S., Kan, X. H., Wang, H., Xiong, Y. J., \& Wu, G. C. (2021). Mental health problems and social supports in the COVID-19 healthcare workers: A Chinese explanatory study. BMC Psychiatry, 21(1), 1-8. https://doi.org/10.1186/ s12888-020-02998-y

Fenlason, K. J., \& Beehr, T. A. (1994). Social support and occupational stress: Effects of talking to others. Journal of Organizational Behavior, 15(2), 157-175. https://doi.org/10.1002/job. 4030150205

Fitzpatrick, K. M., Harris, C., \& Drawve, G. (2020). Fear of COVID-19 and the mental health consequences in America. Psychological Trauma: Theory, Research, Practice, and Policy, 12(1), 17-21. https://doi.org/10.1037/tra0000924

Gao, J., Zheng, P., Jia, Y., Chen, H., Mao, Y., \& Chen, S. (2020). Mental health problems and social media exposure during COVID-19 outbreak. PLoS ONE, 15(4), 1-10. https://doi.org/10.1371/journ al.pone.0231924

Gomendio, M. (2017). Empowering and enabling teachers to improve equity and outcomes for all, international summit on the teaching profession, Paris, OECD Publishing. Retrieved 3 April 2021 from: https://doi.org/10.1787/9789264273238-en.

Grey, I., Arora, T., Thomas, J., Saneh, A., Tohme, P., \& Abi-Habib, R. (2020). The role of perceived social support on depression and sleep during the COVID-19 pandemic. Psychiatry Research, 293, 1-6. https://doi.org/10.1016/j.psychres.2020.113452

Gündoğan, S. (2021). The mediator role of the fear of covid-19 in the relationship between psychological resilience and life satisfaction. Current Psychology: A Journal for Diverse Perspectives on Diverse Psychological Issues. Advance online publication. https:// doi.org/10.1007/s12144-021-01525-w

Gülaçt1, F. (2010). The effect of perceived social support on subjective well-being. Procedia-Social and Behavioral Sciences, 2(2), 3844-3849.

Haktanir, A., Seki, T.,\& Dilmaç, B. (2020). Adaptation and evaluation of Turkish version of the fear of COVID-19 scale. Death Studies, 1-9. https://doi.org/10.1080/07481187.2020.1773026

Huang, C., Wang, Y., Li, X., Ren, L., Zhao, J., Hu, Y., \& Cao, B. (2020). Clinical Features of Patients Infected with 2019 Novel Coronavirus in Wuhan China. The Lancet, 395(10223), 497-506.

Hupcey, J. E. (1998). Social support: Assessing conceptual coherence. Qualitative Health Research, 8(3), 304-318. https://doi.org/10. $1177 / 104973239800800302$

Korte, D. S., \& Simonsen, J. C. (2018). Influence of social support on teacher self-efficacy in novice agricultural education teachers. Journal of Agricultural Education, 59(3), 100-123. https://doi. org/10.5032/jae.2018.03100

Labrague, L. J., \& De los Santos, J. A. A. (2020). COVID-19 anxiety among front-line nurses: Predictive role of organisational support, personal resilience and social support. Journal of Nursing Management, 28(7), 1653-1661. https://doi.org/10.1111/jonm.13121

Li, F., Luo, S., Mu, W., Li, Y., Ye, L., Zheng, X., ... \& Chen, X. (2021). Effects of sources of social support and resilience on the mental health of different age groups during the COVID-19 pandemic. BMC psychiatry, 21(1), 1-14. https://doi.org/10.1186/ s12888-020-03012-1

Little, T. D., Cunningham, W. A., Shahar, G., \& Widaman, K. F. (2002). To parcel or not to parcel: Exploring the question, weighing the merits. Structural Equation Modeling: A Multidisciplinary Journal, 9, 151-173. https://doi.org/10.1207/s15328007s em0902_1

Major, B., Cozzarelli, C., Sciacchitano, A. M., Cooper, M. L., Testa, M., \& Mueller, P. M. (1990). Perceived social support, selfefficacy, and adjustment to abortion. Journal of Personality and Social Psychology, 59(3), 452-463. https://doi.org/10.1037/00223514.59.3.452

Mert, A., \& İskender, M. (2015). Systemic family oriented program of psycho-education, effect of values of spouses and perceived social support on dyadic adjustment. The International Journal of Human and Behavioral Science, 1(3), 1-12. https://doi.org/10. 19148/ijhbs. 81297

Mumtaz, A., Manzoor, F., Jiang, S., \& Anisur Rahaman, M. (2021). COVID-19 and mental health: A study of stress, resilience, and depression among the older population in Pakistan. Healthcare, 9(4), 1-13.

Moore, S. E., Wierenga, K. L., Prince, D. M., Gillani, B., \& Mintz, L. J. (2021). Disproportionate impact of the COVID-19 pandemic on perceived social support, mental health and somatic symptoms in sexual and gender minority populations. Journal of Homosexuality, 68(4), 1-15. https://doi.org/10.1080/00918369.2020.1868184

Okan, N. (2021). Investigation of the moderator effect of the fear of covid-19 in the relation between communication anxiety and self-efficacy. Educational Process: International Journal, 10(3), 62-77. https://doi.org/10.21203/rs.3.rs-484473/v1

Poudel, A., Gurung, B., \& Khanal, G. P. (2020). Perceived social support and psychological wellbeing among Nepalese adolescents: The mediating role of self-esteem. BMC Psychology, 8, 1-8. https://doi.org/10.1186/s40359-020-00409-1

Saltzman, K. M., \& Holahan, C. J. (2002). Social support, self-efficacy, and depressive symptoms: An integrative model. Journal of Social and Clinical Psychology, 21(3), 309-322. https://doi.org/10.1521/ jscp.21.3.309.22531

Sarıçalı, M., Satıcı, S. A., Satıcı, B., Göçet-Tekin, E., \& Griffiths, M. D. (2020). Fear of COVID-19, mindfulness, humor, and hopelessness: A multiple mediation analysis. International Journal of Mental Health and Addiction. https://doi.org/10.1007/ s11469-020-00419-5

Satıc1, B., Göçet-Tekin, E., Deniz, M. E., \& Satıcı, S. A. (2020a). Adaptation of the Fear of COVID-19 Scale: Its association with psychological distress and life satisfaction in Turkey. International Journal of Mental Health and Addiction. https://doi.org/10.1007/ s11469-020-00294-0

Satıcı, B., Sarıçalı, M., Satıcı, S. A., \& Griffiths, M. D. (2020b). Intolerance of uncertainty and mental wellbeing: Serial mediation by rumination and fear of COVID-19. International Journal of Mental Health and Addiction. https://doi.org/10.1007/ s11469-020-00305-0

Schermelleh-Engel, K., Moosbrugger, H., \& Müller, H. (2003). Evaluating the fit of structural equation models: Tests of significance and descriptive goodness-of-fit measures. Methods of Psychological Research Online, 8(2), 23-74.

Schwarzer, R., \& Jerusalem, M. (1995). Generalized Self-efficacy Scale. In J. Weinman, S. Wright, \& M. Johnston (Eds.), Measures in health psychology: A user's portfolio. Causal and control beliefs (pp. 35-37). NFER-Nelson. 
Shanafelt, T., Ripp, J., \& Trockel, M. (2020). Understanding and addressing sources of anxiety among health care professionals during the COVID-19 pandemic. Journal of American Medical Association, 323(21), 2133-2134. https://doi.org/10.1001/jama. 2020.5893

Skalski, S., Konaszewski, K., Dobrakowski, P., Surzykiewicz, J., \& Lee, S. A. (2021a). Pandemic Grief in Poland: Adaptation of a measure and its relationship with social support and resilience. Psiarchive. https://doi.org/10.31234/osf.io/es3rd

Skalski, S., Uram, P., Dobrakowski, P., \& Kwiatkowska, A. (2021b). The link between ego-resiliency, social support, SARS-CoV-2 anxiety and trauma effects. Polish adaptation of the Coronavirus Anxiety Scale. Personality and Individual Differences, 171, 1-7. https://doi.org/10.1016/j.paid.2020.110540

Tabachnick, B. G., \& Fidell, L. S. (2013). Using multivariate statistics. Pearson Education.

Taşçı, S. (2021). Evaluation of emergency distance language education: Perspectıves of elt students. Nevşehir Hacı Bektaş Veli University Journal of Social Sciences Institute, 11(1), 286-300. https://doi. org/10.30783/nevsosbilen.877657

Towner, L. (1998). Managing employee stress: Support your staff by preventing or reducing stress in the workplace with this step-bystep guide. Kogan Page.

Tull, M. T., Edmonds, K. A., Scamaldo, K. M., Richmond, J. R., Rose, J. P., \& Gratz, K. L. (2020). Psychological outcomes associated with stay-at-home orders and the perceived impact of COVID-19 on daily life. Psychiatry Research, 289, 1-6. https://doi.org/10. 1016/j.psychres.2020.113098

Wang, C., Pan, R., Wan, X., Tan, Y., Xu, L., Ho, C. S., \& ve Ho, R.C. . (2020). Immediate psychological responses and associated factors during the initial stage of the 2019 coronavirus disease (COVID19) epidemic among the general population in China. International Journal of Environmental Research and Public Health, 17, 1-25. https://doi.org/10.3390/ijerph17051729

World Health Organization. (2020). Coronavirus disease 2019 (COVID19) Situation Report - 51. Retrieved 5 Sem 2020 from https:// www.who.int/docs/defaultsource/coronaviruse/situationreports/ 20200311-sitrep-51-covid-19.pdf?sfvrsn=1ba62e57_10

World Health Organization. (2021a). Coronavirus disease 2019 (COVID-19) situation report. Retrieved 14 April 2021 from: https://www.who.int/emergencies/diseases/novel-coron avirus-2019

Yakut, E., Kuru, Ö., \& Güngör, Y. (2020). Determination of the influence of work overload and perceived social support in the effect of the COVID-19 fears of health care personnel on their burnout by structural equation modelling. Ekev Journal of Academia, 24(83), 241-262.

Ye, Z., Yang, X., Zeng, C., Wang, Y., Shen, Z., Li, X., \& Lin, D. (2020). Resilience, social support, and coping as mediators between COVID-19-related stressful experiences and acute stress disorder among college students in China. Applied Psychology: Health and Well-Being, 12(4), 1074-1094. https://doi.org/10. 1111/aphw.12211

Yusoff, Y. M. (2012). Self-efficacy, perceived social support, and psychological adjustment in international undergraduate students in a public higher education institution in Malaysia. Journal of Studies in International Education, 16(4), 353-371. https://doi.org/10. $1177 / 1028315311408914$

Zandifar, A., \& Badrfam, R. (2020). Iranian mental health during the COVID-19 epidemic. Asian Journal of Psychiatry, 51, 101990. https://doi.org/10.1016/j.ajp.2020.101990

Zhou, P., Yang, X. L., Wang, X. G., Hu, B., Zhang, L., Si, H. R., \& Shi, Z.-L. (2020). A pneumonia outbreak associated with a new coronavirus of probable bat origin. Nature, 559, 270-289. https:// doi.org/10.1038/s41586-020-2012-7

Zimet, G. D., Dahlem, N. W., Zimet, S. G., \& Farley, G. K. (1988). The Multidimensional Scale of Perceived Social Support. Journal of Personality Assessment, 52(1), 30-41. https://doi.org/10.1207/ s15327752jpa5201_2

Zimmerman, B. J. (1989). Models of self-regulated learning and academic achievement. In B. J. Zimmerman \& D. H. Schunk (Eds.), Self-regulated learning and academic achievement theory, research, and practice (pp. 1-25). Springer.

Publisher's note Springer Nature remains neutral with regard to jurisdictional claims in published maps and institutional affiliations. 